\title{
MOVIMENTO DOS SENTIDOS DE PROFESSORAS SOBRE O LÚDICO: IMPLICAÇÕES PARA AS PRÁTICAS DE EDUCAÇÃO MATEMÁTICA NA EDUCAÇÃO INFANTIL
}

\author{
THE MOVEMENT OF TEACHER'S SENSES ABOUT LUDIC: IMPLICATIONS \\ FOR MATHEMATICS EDUCATION PRACTICES IN EARLY CHILDHOOD \\ EDUCATION
}

\author{
Juliana Ribeiro Andrade \\ Universidade Federal de São Paulo - UNIFESP \\ andrade30juliana@gmail.com \\ Vanessa Dias Moretti \\ Universidade Federal de São Paulo - UNIFESP \\ vanessa.moretti@unifesp.br
}

\begin{abstract}
Resumo
$\mathrm{O}$ artigo apresenta parte de uma pesquisa de mestrado que investigou a relação dos sentidos pessoais, de cinco professoras da Educação Infantil e anos iniciais do Ensino Fundamental, sobre a ludicidade e práticas de Educação Matemática no contexto de uma formação continuada que problematizou o lúdico, a coletividade e a organização do ensino à luz da Teoria Histórico-Cultural e da Teoria da Atividade. Os dados analisados foram coletados por meio de registros orais e escritos de discussões, relatos e desenvolvimento de Situações Desencadeadoras de Aprendizagem. Para fins desse artigo, analisamos o movimento de sentido sobre ludicidade da professora de Educação Infantil Telma. Os resultados mostram que, no decorrer do processo analisado, os motivos da professora para inserir elementos lúdicos nas suas práticas de educação matemática foram impactados, o que implicou em mudanças na organização do ensino à medida que a ludicidade e o brincar passam a ser compreendidos como uma vivência desenvolvente e como a atividade principal da criança. Considerando a relevância da temática do brincar na infância, os resultados da pesquisa reforçam a importância dos espaços coletivos de formação docente e das contribuições das ações formativas ancoradas na Teoria Histórico-Cultural, como desencadeadores da produção de novas práticas lúdicas de educação matemática na Educação Infantil.

Palavras-chave: Ludicidade; Organização do ensino; Educação Matemática; Educação Infantil; Teoria da Atividade; Teoria Histórico-Cultural.
\end{abstract}

\begin{abstract}
The article presents part of a master's research that investigated the relationship of personal senses, of five teachers in Early Childhood Education and early years of Elementary School, on ludic activities and Mathematical Education practices in the context of continuous teacher training that problematized ludic, collectivity and organization of teaching in the light of Historical-Cultural Theory and Activity Theory. The analyzed data were collected through oral and written records of
\end{abstract}


discussions, reports and the development of Triggering Situations of Learning. For the purposes of this article, we analyze the movement of the senses about the ludic of the Early Childhood Education teacher Telma. The results show that, while the analyzed process, the teacher's motives for inserting ludic elements in her mathematics education practices were impacted, which implied changes in the organization of teaching as ludicity and play come to be understood as a developmental experience and as the child's main activity. Considering the relevance of the theme of playing in childhood, the results of the research reinforce the importance of collective spaces for teacher education and the contributions of training actions anchored in Historical-Cultural Theory, as triggers to produce new ludic practices in mathematics education in Early Childhood Education. Keywords: Ludicity; Organization of teaching; Mathematical Education; Early Child Education; Activity Theory; Historical-Cultural Theory.

\section{INTRODUÇÃO}

Educação Infantil é lugar de brincar? Educação Infantil é lugar de aprender? Ou será que as duas coisas? E onde entra a aprendizagem matemática nessa conversa? E o professor da Educação Infantil pode ensinar Matemática ou deve criar espaços de brincadeiras?

Partindo dessas inquietações, desenvolvemos uma pesquisa de mestrado (ANDRADE, 2020) que teve por motivação melhor compreender as relações entre o brincar, as aprendizagens matemáticas o trabalho do professor da Educação Infantil uma vez que, de acordo com Moura (2002), é por meio das brincadeiras que a criança se relaciona com o mundo e compreende as relações humanas à medida que as vivencia, experimenta papéis e se desenvolve.

Tomando a problemática da relação entre a ludicidade na Educação Infantil e o papel do professor que ensina Matemática na infância, a pesquisa tomou como referencial a Teoria Histórico-Cultural (VIGOTSKI, 2010) e a Teoria da Atividade (LEONTIEV, 1988) e investigou o movimento de sentidos pessoais de cinco professoras da Educação Infantil e anos iniciais do Ensino Fundamental sobre a ludicidade e como esse movimento de sentidos impactou as suas práticas em sala de aula no que diz respeito às práticas de Educação Matemática e sua organização.

Para os fins desse artigo trazemos um recorte dos dados da referida pesquisa ao apresentarmos a análise do movimento da professora Telma e buscamos mostrar como o movimento de sentidos da professora sobre a noção de lúdico impactou a organização de práticas lúdicas no processo de ensino e aprendizagem de matemática na sala de aula da Educação Infantil. 
Com esse objetivo, partimos de uma breve apresentação de princípios e conceitos fundamentais da teoria que nos embasa e que são essenciais na análise que propomos, tais como o próprio conceito de atividade, o papel do professor no processo educativo, a noção de brincar e lúdico como uma atividade desenvolvente da infância e, portanto, um importante mediador do processo de ensino e aprendizagem na Educação Infantil. Na sequência, trazemos elementos da metodologia da pesquisa à qual esse artigo se refere $\mathrm{e}$ apresentamos os dados selecionados. Por fim, considerando nossas análises, realizamos uma discussão sobre a importância do espaço coletivo de formação de professores e conclusões da pesquisa.

\section{A ATIVIDADE HUMANA E O DESENVOLVIMENTO DOS SUJEITOS}

Alguns elementos propostos na Teoria Histórico-Cultural (VIGOTSKI, 2010) trazem impactos importantes ao pensarmos o processo educativo e o papel da escola. Ao propor que o homem se humaniza ao se apropriar de elementos da cultura, por meio das relações sociais que estabelece com outros sujeitos no meio social, Vigotski entende que as funções do psiquismo, tais como memória e linguagem, tipicamente humanas - as funções psicológicas superiores (VIGOTSKI, 2010) - são funções psíquicas mediadas. Assim, Vigotski (2010) caracteriza o homem como um ser social que, ao socializar com seus pares, se apropria da cultura humana construída ao longo do tempo, ao mesmo tempo em que pode transformá-la, numa relação dialética.

Ao se apropriarem, ou seja, internalizarem e reproduzirem partes da cultura, num processo mediatizado por relações sociais, os sujeitos desenvolvem seu psiquismo. Para Davidov e Markóva (1987), o conceito de apropriação é compreendido como:

A reprodução pela criança da experiência socialmente elaborada e o ensino é a forma de organização desta apropriação, aceita nas condições históricas concretas, na sociedade dada, o desenvolvimento se caracteriza, antes de tudo, nos avanços qualitativos no nível e nas formas das capacidades, nos tipos de atividade, etc. do que se apropria o indivíduo (DAVIDOV E MARKÓVA, 1987, p. 322, tradução nossa).

Ao abordar os processos de ensino e aprendizagem de matemática na infância à luz da Teoria Histórico-Cultural, Moura (2002), afirma que:

Pertencer a uma cultura, é ter de se apoderar de um conjunto de conhecimentos que permita estar entre os sujeitos e trocar significados com eles, poder compartilhar conhecimentos para juntos construírem novos modos de viver cada vez melhores. Ser sujeito na cultura em que foi inserido implica poder apoderar- 
se dos instrumentos simbólicos desta cultura para com eles atuar, criar e intervir na sociedade recém-adotada (MOURA, 2002, p. 41)

Tal pressuposto, nos permite compreender a importância da escola enquanto um espaço coletivo de mediação que tem como objetivo a sistematização e apropriação de conhecimentos e outros elementos da cultura humana.

Dando continuidade às ideias de Vigotski, Leontiev (1988) propõe que o processo pelo qual o homem se desenvolve ao se apropriar de elementos da cultura humana é a atividade humana (LEONTIEV, 1988). Assim, é por meio das atividades humanas, entendidas como processos mediatizados, que nos relacionamos com o mundo a nossa volta, nos apropriando de elementos construídos ao longo dos anos pela humanidade, desenvolvendo nosso psiquismo (LEONTIEV, 1988) e nos transformando ao mesmo tempo em que transformamos a realidade na qual estamos inseridos.

$\mathrm{Na}$ definição de Leontiev as atividades humanas são "processos que, realizando as relações do homem com o mundo, satisfazem uma necessidade especial correspondente a ele" (LEONTIEV, 1988, p. 86). Portanto, toda atividade humana parte de alguma necessidade que mobiliza os indivíduos a agir no decorrer desse processo. Como parte da estrutura das atividades humanas, Leontiev (1988) destaca a necessidade - que deve ser intencional e consciente e, portanto, mobilizadora da atividade; os motivos (que a direcionam), o objeto (para qual a atividade se dirige), ações e operações (que são modos de agir para torná-la possível). Nas palavras de Moura (2002, p. 43), "as necessidades humanas constituem-se como o motor do desenvolvimento da humanidade".

Para exemplificar, vamos imaginar um professor em atividade de ensino, a partir da necessidade de que as crianças se apropriem de conhecimentos culturais. Esse professor pode lançar mão de ações como propor rodas de conversas, apresentar jogos, contar histórias etc. Cada uma dessas ações, pode ser objetivada por meio de diferentes operações que são as condições objetivas de realização de uma ação. Assim, por exemplo, para contar uma história, a professora pode narrá-la de forma teatralizada, pode usar um vídeo ou mesmo ler um livro.

No decorrer das atividades, os sujeitos se apropriam de modos de ações, conhecimentos científicos, papéis sociais, conceitos e outros elementos da cultura construídos ao longo do tempo pela humanidade e esses elementos, cristalizados na cultura, 
são as significações. Nessa direção, compreendemos que, "a significação é a generalização da realidade que é cristalizada e fixada num vector sensível, ordinariamente a palavra ou a locução. É a forma ideal, espiritual da cristalização da experiência e da prática sociais da humanidade" (LEONTIEV, 1978a, p. 94). De forma dialética, há nesse processo a produção de sentidos pessoais que representam a relação dos sujeitos com seu contexto social e são atribuídos na vivência e relação dos indivíduos com o mundo ao seu redor. Partindo da teoria de Leontiev (1988), compreendemos também uma relação intrínseca entre sentidos pessoais e motivos no âmbito da atividade humana, principalmente porque os sentidos atribuídos pelos sujeitos ao longo da vida têm um impacto direto no motivo da atividade.

A relação entre significados sociais e sentidos pessoais (LEONTIEV, 1978b) é fundamental para bem compreendermos a investigação que foi desenvolvida e a análise da relação entre o movimento dos sentidos sobre o lúdico - desencadeado no espaço coletivo de forma mediada por significados sociais - e mudança na atividade de ensino do professor que resultou na mudança de prática em sala de aula.

A seguir, apresentamos algumas contribuições da Teoria Histórico-Cultural na defesa do papel da Educação Infantil e as possibilidades de aprendizagens matemáticas nessa etapa do desenvolvimento infantil.

\section{Educação Matemática na Educação Infantil: Caminhos e perspectivas}

$\mathrm{Na}$ Teoria Histórico-Cultural a escola é compreendida como o lugar social planejado para a apropriação intencional de elementos da cultura humana entendidos como relevantes o suficiente para serem transmitidos para outras gerações (MOURA, 2006). Mas qual a especificidade da Educação Infantil?

Para entender essa questão precisamos recorrer ao conceito de atividade dominante (LEONTIEV, 1988). Para esse pesquisador, cada período ou fase da vida é marcado por uma atividade dominante que está relacionada com um desenvolvimento mais amplo do psiquismo dos indivíduos. Essa atividade é denominada como atividade principal e é aquela "cujo desenvolvimento governa as mudanças mais importantes nos processos psíquicos e nos traços psicológicos da personalidade da criança, em um certo estágio do seu desenvolvimento" (LEONTIEV, 1988, p. 65). Desse modo, temos uma atividade dominante em cada fase da vida, ainda que a existência dessa atividade principal não anule a coexistência de outras atividades (FACCI, 2004). 
No caso da criança na Educação Infantil, fase que antecede o ingresso no Ensino Fundamental, a criança tem como atividade principal o brincar; já na fase escolar, a atividade principal dessa criança gradativamente transforma-se no estudo ${ }^{1}$. Assim, o brincar é a atividade que possibilita o maior desenvolvimento psíquico nessa fase da vida da criança na Educação Infantil de modo que a criança se apropria do mundo ao seu redor (e, portanto, de noções e conhecimento matemático), por meio da ludicidade.

[...] no período pré-escolar, a atividade principal passa a ser o jogo ou a brincadeira. Utilizando-se dessas atividades, a criança apossa-se do mundo concreto dos objetos humanos, por meio da reprodução das ações realizadas pelos adultos com esses objetos. As brincadeiras das crianças não são instintivas e o que determina seu conteúdo é a percepção que a criança tem do mundo dos objetos humanos. A criança opera com os objetos que são utilizados pelos adultos e, dessa forma, toma consciência deles e das ações humanas realizadas com eles (FACCI, 2004, p. 67).

Ao citar o jogo e o brincar como atividades fundamentais e desenvolventes da Educação Infantil, ampliamos nossa perspectiva sobre essas atividades para além do jogo, elencando as vivências e práticas lúdicas como atividades essenciais desta fase. Nossa compreensão sobre o lúdico se apoia em Vigotski (2000) que o considera como uma atividade humana que gera "certas necessidades da criança" (p. 122). Ou seja, atribuímos o caráter de ludicidade às práticas que são interessantes e mobilizadoras da infância, que despertam uma necessidade e incitam a criança a agir, como as rodas de conversas, contações de história, jogos de faz-de-conta, jogos de regras, brincadeiras com uso de brinquedos e outras práticas amplamente possíveis. Assim, o aspecto lúdico ganha importância enquanto um mediador do processo de ensino e aprendizagem na Educação Infantil. Ou seja, um recurso que, utilizado intencionalmente pelo professor, pode atuar como mediador no processo de apropriação de elementos culturais como conceitos, valores, arte etc. no processo de aprendizagem.

Por meio da brincadeira, a criança pode se apropriar de conhecimentos, modos de ações e papéis sociais que ainda não domina. Podemos dizer que ao brincar a criança age na Zona de Desenvolvimento Proximal (ZPD) que, de acordo com Vigotski (1991), é a distância entre aquilo que a criança realiza sozinha e o que ela realiza sob o auxílio de um par mais capaz. Assim, a ludicidade pode favorecer o desenvolvimento psíquico das

\footnotetext{
${ }^{1}$ Um detalhamento das atividades principais ou dominantes ao longo da vida pode ser encontrado em Facci (2004).
} 
crianças tanto porque permite à criança vivenciar diferentes papéis sociais, produzindo sentidos sobre significados sociais, quanto por mobilizar a criança a agir, descobrindo modos de ação e, portanto, estimulando-a a avançar para além das suas aprendizagens e apropriações já realizadas.

Partindo da importância do lúdico para a criança na sua relação com o mundo e processo de apropriação de elementos da cultura, entendemos que a ludicidade deva ser parte intencional do trabalho do professor na Educação Infantil, com o objetivo de possibilitar que a criança aprenda e se desenvolva. Nesse contexto, temos, portanto, dois sujeitos em atividade: a criança, cuja atividade principal é o brincar e o jogar e tem suas necessidades suscitadas e mobilizadas diante do lúdico; e o professor, cuja atividade é o ensino e, nesse caso, sua necessidade é a apropriação de elementos da cultura por seus alunos.

Sendo assim, é essencial que o professor compreenda como as crianças aprendem em cada fase do seu desenvolvimento, tomando os melhores caminhos e decisões intencionais para organizar o ensino, promovendo um desenvolvimento amplo e possível no processo de aprendizagem. No caso da Educação Infantil, período no qual o lúdico é a atividade principal, as práticas devem ser pautadas em brincadeiras, jogos, vivências que suscitem a necessidade da criança baseada nessas práticas.

Priorizar o amplo desenvolvimento da criança passa por possibilitar também a aprendizagem de conhecimentos matemáticos. Segundo Moura (2002), apropriar-se dos saberes matemáticos significa apropriar-se de um instrumento lógico e simbólico fundamental para compreender o mundo no qual a criança está inserida (MOURA, 2002). Além disso, para garantir uma aprendizagem é fundamental colocar o pensamento da criança em movimento ao colocá-la em busca de uma solução para determinada situação planejada para gerar necessidades, inserindo-a no contexto enfrentado pela humanidade para a construção de determinado conceito:

A possibilidade de colocar a criança num movimento de construção de conhecimentos matemáticos para a vida é introduzir no jogo a necessidade da utilização desses conhecimentos de forma significativa. Fazer isso é colocar o pensamento da criança em acção, em situações interactivas, de modo que os sujeitos tenham a necessidade de construir coletivamente a solução de situaçõesproblemas. Ao utilizar os instrumentos simbólicos de que dispõe, a criança irá incorporando novos conceitos para a solução que lhe é proposta. Também irá construindo modos de acção que lhe permitirão utilizá-los noutras situações semelhantes (MOURA, 2002, p. 61). 
Nessa relação dialética entre as atividades da criança e atividade do professor, que acontecem como processos intimamente interligados e dependentes, os motivos, necessidades e sentidos dos sujeitos estão sempre em movimento uma vez que "a atividade de ensino do professor deve gerar e promover a atividade do estudante, deve criar nele um motivo especial para a sua atividade" (MOURA et al., 2010, p. 213). Esta é a proposta do conceito de Atividade Orientadora de Ensino (AOE) que compreende as atividades do aluno e professor como parte de um mesmo processo, em constante movimento (MOURA, 1996; MOURA et al., 2010). A AOE propõe que o professor tem o desafio de criar Situações Desencadeadoras de Aprendizagem (SDA) que suscitem as necessidades para que seus alunos entrem em atividade. No caso das crianças, cuja atividade principal é o brincar, podemos recorrer a instrumentos como o jogo, as histórias virtuais e as situações emergentes do cotidiano, priorizando as práticas coletivas de discussão que permitem a busca conjunta pela solução de um problema gerado no contexto da situação desencadeadora (MOURA, 1996; MOURA et. al., 2010).

Como veremos a seguir, a proposta da AOE teve papel importante no andamento do experimento formativo realizado como parte da pesquisa.

\section{CAMINHOS METODOLÓGICOS}

Para investigarmos o movimento de sentidos de professoras sobre o lúdico e o impacto desses sentidos na organização do ensino, partimos da compreensão teórica da relação entre motivo e sentido pessoal nas atividades humanas (LEONTIEV, 1988) e buscamos desencadear esse movimento por meio da apropriação de novos conceitos relacionados ao lúdico e discussão de práticas, o que foi possível por meio de um experimento formativo (CEDRO e MOURA, 2012). A estratégia metodológica do experimento formativo é coerente com a fundamentação teórica da pesquisa uma vez que permite a análise da essência do fenômeno, a ideia de movimento ao longo dessa análise e uma explicação (e não uma mera descrição) do fenômeno estudado (MORETTI, MARTINS e SOUZA, 2016). O experimento deu-se na forma de uma formação continuada de professores no ano de 2019 com encontros semanais entre os meses de abril a setembro, em uma escola pública localizada no município de Guarulhos, no Estado de São Paulo. O grupo de educadores foi composto por sete professoras da Educação Infantil e anos iniciais 
do Ensino Fundamental, uma coordenadora pedagógica, duas estagiárias e um professor de Educação Física.

Dentre as ações formativas desenvolvidas no experimento propusemos a discussão de temas relacionados com a organização das práticas de Educação Matemática na infância, tais como, a noção de ludicidade, o papel do lúdico como mediador dessas práticas (GRANDO, 2008), as contribuições da Atividade Orientadora de Ensino (MOURA, 1996; MOURA et al., 2010) e as ideias de Clubes de Matemática (CEDRO, 2004; MORETTI, 2014) como inspiradores de práticas do ensino de matemática pautados na ludicidade e na AOE. Além dessas propostas, também tivemos como ações formativas as vivências de momentos lúdicos para a aprendizagem de noções matemáticas, criados por meio de jogos e uma história virtual (MOURA et al., 2010). Ao final, foi proposto aos educadores um movimento coletivo de planejamento, desenvolvimento, avaliação e replanejamento de ações com as crianças em sala de aula, por meio de dois planos de aula elaborados e desenvolvidos pelas professoras.

As gravações dos encontros, o diário de campo da pesquisadora, as produções dos educadores, planos de aula e imagens das ações realizadas pelas professoras feitas por elas mesmas, constituíram os dados da pesquisa. Para a análise de dados em nosso artigo, trazemos trechos e recortes das contribuições de uma professora ao longo dos encontros formativos: suas falas, relatos pessoais sobre práticas em sala de aula e sua formação, planos de aula e relatos de seus desenvolvimentos com a turma - esses elementos foram analisados à luz dos norteadores teóricos de modo a compreender os sentidos pessoais da professora sobre o lúdico e os impactos desses sentidos em suas práticas de Educação Matemática.

Para fins desse artigo, apresentamos a análise do movimento da professora Telma, professora de uma turma de crianças de 4 anos, da Educação Infantil.

\section{MOVIMENTO DOS SENTIDOS PESSOAIS SOBRE O LÚDICO E IMPACTOS NA ORGANIZAÇÃO DO ENSINO DE MATEMÁTICA NA EDUCAÇÃO INFANTIL: O CASO DA PROFESSORA TELMA}

A professora Telma possuía oito anos de experiência em sala de aula e estava à frente de uma turma da Educação Infantil, no estágio I (com crianças com 4 anos de idade). Já nos primeiros encontros a professora manifesta indícios de seus sentidos iniciais sobre 
a ludicidade e o relato de algumas de suas práticas em sala de aula.

No primeiro momento, Telma demonstra compreender o lúdico como equivalente à ideia de agir no concreto, considerando como brincadeiras o manuseio de peças de montar, palitos e outros materiais concretos para a contagem de modo que, para ela, o brincar e o jogar estavam relacionados ao manuseio de brinquedos que, naquele movimento, eram descaracterizados como brinquedos e se tornavam material de apoio para contagem. Esses indícios pessoais ficam claros no seguinte relato pessoal (RP) da professora Telma, durante o segundo encontro formativo (E2):

Esse ano estou com o infantil e eu estou procurando outras maneiras também... Não só ficar lá, "olha, esse é o número 1, faz um desenho", mas trabalhar a partir de coisas que interessem pra eles, que você vê que eles estão gostando. Essa parte mais concreta: material dourado, trabalhar palito, essas coisas (Telma, RP, $\mathrm{E} 2)$.

A ideia de contagem com pecinhas de montar, partindo de um comando da professora, embora possa ser interessante em alguns contextos, não apresenta uma prática lúdica, relacionada ao brincar como foco do interesse da criança. Assim, a criança realiza a ação porque é orientada a fazê-lo pela professora e não porque a proposta gere uma necessidade ou um motivo eficaz (LEONTIEV, 1988) para o agir.

Nessa aproximação inicial em relação aos sentidos pessoais sobre o lúdico e sobre as práticas em sala de aula, a professora Telma relata uma proposta que ela avalia como mais interessante (ou mais "gostosa", nas palavras da própria professora) para seus alunos e que tinha como objetivo a medição de superfícies, de acordo com o relato pessoal (RP) da professora, no segundo encontro formativo (E2):

\footnotetext{
Aí a gente fez a pesagem, medimos a altura, toda essa parte e eu achei bem legal. Cansativo, mas foi bem marcante para eles, trabalhar essa parte lúdica, levar a fita métrica, medir. Eles mediram várias coisas. O EMAI traz isso, além de eles trabalharem no livro, eles fazerem também. Eu achei a linguagem deles mais fácil e aí me deu vontade de fazer as atividades, não só de apresentar. (Telma, $\mathrm{RP}, \mathrm{E} 2)$.
}

Neste trecho, apesar da relação entre lúdico e concretude se manter nos indícios de sentidos iniciais, a professora Telma traz um relato em que caracteriza a vivência de medição com fita métrica como uma "parte lúdica", relacionando a ludicidade como uma prática que possibilitaria que os alunos "fizessem" experimentações para além dos estudos no livro. Assim, parece que a professora Telma também considera como lúdicas as vivências nas quais as crianças são mobilizadas por uma necessidade, em uma situação 
prática que desencadeie movimento. Tais práticas, segundo a professora, além de mobilizarem as crianças, também despertaram nela a vontade de participar. Apesar de manifestar dar importância à tais práticas mobilizadoras, a professora Telma não viabiliza essa dimensão em suas práticas que continuam ligadas ao manuseio de objetos concretos a partir de um comando específico.

Entendemos que o fato de as ações das crianças resultarem de um comando específico da professora empobrece a atividade lúdica uma vez que a necessidade da criança, nesse contexto, seria obedecer a orientação da professora e não agir para atingir a um objetivo da brincadeira. Assim, é possível que a criança não entre em atividade lúdica o que, caso ocorresse, potencializaria a apropriação das noções matemáticas de contagem, objetivadas pela educadora.

Figura 1 - Sentidos iniciais e organização do ensino da professora Telma

\section{Sentidos iniciais}

Lúdico entendido como Concretude

\section{Organização do ensino de matemática} Utilização de materiais concretos e brinquedos para contagem. Brinquedos são descaracterizados e perdem função de mediar o ato de brincar.

Fonte: Das autoras.

Após o levantamento de indícios dos sentidos iniciais e práticas de Educação Matemática em sala de aula, organizamos um segundo bloco de ações formativas que consistiam em situações de estudos teóricos sobre ludicidade, AOE e Clubes de Matemática. Neste bloco foi possível verificar que os sentidos iniciais da professora Telma, destacados na figura 1, ainda se manifestaram da mesma forma, ou seja, revelando a equivalência entre o concreto e o lúdico. Tal análise fica clara, pois a professora realiza um relato sobre a sua prática durante o décimo encontro formativo (E10) no qual, a partir do estudo das contribuições da Atividade Orientadora de Ensino (MOURA, 1996), houve uma discussão coletiva (DC) sobre as relações possíveis dessa proposta com a prática em sala de aula. Nesse contexto, a professora Telma relata:

Eu queria fazer a atividade do bolo com eles, de quantos anos eles tem e antes de fazer eu perguntei a idade e pedi para eles pegarem as pecinhas, e aí eu fiz os números da idade e colei neles... Nisso, eles conseguiram fazer bem a atividade do bolo...Eles tiveram um pouco de dificuldade com a escrita, mas eu ajudei. Tipo eu perguntava quantos eles tinham, aí eles respondiam a quantidade e pagavam o número de pecinhas correspondentes... Eu fiz o número e colei neles, só para ver se eles conseguiam guardar na cabeça... (Telma, DC, E10). 
A "atividade do bolo", proposta pela professora, propunha que as crianças representassem suas idades sobre o desenho de um bolo, partindo de um enunciado simples. O relato da professora Telma nesse trecho da discussão coletiva faz referência às práticas que mantêm a concretude como mediadora da ação da criança, como a proposta de manuseio de objetos concretos para demonstrar a idade. Entendemos que embora esse tipo de proposta até possa mobilizar as crianças, uma vez que elas são autorizadas a se movimentarem pela classe, ela não se caracteriza como uma vivência lúdica que tome como referência o brincar como a atividade principal da criança. Isso porque as ações que a criança realiza são ações que cumprem uma orientação da professora e não ações que resultam da intencionalidade de brincar. Assim, entendemos que a proposta apresentada nesse momento pela professora Telma não suscita na criança um motivo eficaz para a sua ação. Nesse caso, o motivo das crianças é um motivo compreensível (cf. LEONTIEV, 1988): realizar aquilo que foi pedido pela professora.

Seria muito diferente se, por exemplo, para explorar contagem e representação da idade das crianças a professora contasse uma história virtual em que um personagem quisesse preparar um bolo para seu amigo, mas não soubesse exatamente quantas velas colocar no topo desse bolo, pois desconhece sua idade. Vamos imaginar que na história, o personagem relatasse que seu amigo tem a mesma idade das crianças da turma e convidasse a turma a imaginar um bolo (desenhando, usando massa de modelar ou outros materiais), auxiliando o personagem da história a compreender a quantidade de velas, a partir de suas representações sobre suas idades. Nesse exemplo, consideramos que a ludicidade está no movimento da história virtual (MOURA, 1996) que possibilita à criança imaginar e ser parte da história, mobilizando-se diante da necessidade de resolver um problema que a envolve.

Voltando para a análise do movimento da professora Telma, temos que no encontro seguinte (E11), no qual a formadora propôs a discussão sobre os Clubes de Matemática como inspiradores de práticas pautadas na ludicidade e organizados a partir da atividade principal das crianças (CEDRO, 2004; MORETTI, 2014), a professora manifesta um indício de movimento de sentidos ao citar a coletividade como um elemento importante em sala de aula: 
Porque assim [por meio de práticas coletivas] os educandos interagem mais, tendo momentos de reflexões em grupos, auxiliando uns aos outros (Telma, AP, E11).

Nesse trecho de avaliação de percurso (AP) - momento do encontro 11 (E11) no qual as professoras puderam avaliar ações formativas e relatar suas práticas até o momento, a professora dá indícios de estar repensando as próprias práticas, principalmente porque em seus relatos, nos quais as crianças manuseavam objetos concretos, o fazer coletivo não era um elemento evidente.

O terceiro bloco de ações formativas da nossa pesquisa foi marcado pelo movimento coletivo de elaboração de dois planos de aula de maneira livre, contanto que fossem referentes à Educação Matemática. As professoras discutiram suas ideias, organizando-as coletivamente e confeccionando materiais em conjunto. Em seguida, puderam desenvolver esse plano de aula $1 \mathrm{com}$ suas turmas, retornando para o grupo em um movimento coletivo de relato, análise, avaliação e replanejamento para o plano de aula 2. Ao fim do desenvolvimento do plano de aula 2, houve mais uma vez um relato coletivo e avaliação das práticas. Por fim, avaliamos o percurso formativo com o objetivo de compreender as expectativas, aprendizagens e perspectivas dos participantes - formando então o quarto bloco da formação. A seguir, apresentamos a análise do plano de aula 1 (PA1) e o relato pessoal $(\mathrm{RP})$ da professora Telma em relação às práticas desenvolvidas com a turma, destacando indícios de movimentos de sentidos da professora Telma à luz das práticas de Educação Matemática com sua turma.

No relato sobre o plano de aula 1, a professora Telma apresenta que desenvolveu com a turma uma brincadeira musical na qual as crianças foram numeradas de 0 a 10 , depois de terem sido divididas em dois grupos. A professora, com auxílio de uma estagiária, cantava em voz alta a música da serpente, que convidava cada criança a fazer parte de sua cauda, chamando-as de acordo com a ordem numérica, já que cada aluno representava um numeral. Embora a proposta ainda seja protagonizada pela professora, percebemos um movimento de envolver as crianças em um jogo lúdico de movimento e brincadeira através de uma música. Além disso, a proposta suscita nas crianças a necessidade de reconhecer a representação numérica e seguir a música, para poder participar da brincadeira cantada, compondo o corpo da serpente.

Apesar dessa prática denotar indícios da ludicidade, na continuidade da proposta a 
professora Telma relatou que em seguida ao jogo lúdico envolvendo a música, as crianças deveriam retornar para a sala de aula sendo orientadas a pegar peças de montar que representassem dez unidades. Assim, embora haja indícios de que, nesse momento, o lúdico passe a ser parte de sua prática, percebe-se que ele não assume o caráter de prática mobilizadora de aprendizagens que possibilitaria que as crianças se apropriassem da sequência ou representação numérica. Concluímos que, nesse momento, ao inserir a ação mediada pelo elemento concreto depois de propor a vivência lúdica, a professora Telma revela que o uso da prática lúdica tem para ela um motivo compreensível e não eficaz (LEONTIEV, 1988). Ou seja, parece que a inserção do lúdico como prática na Educação Matemática responde a uma demanda do contexto da formação e não a uma compreensão do lúdico como atividade essencial da infância que possibilita o desenvolvimento psíquico e apropriações importantes pela criança.

No relato pessoal da professora Telma sobre o plano de aula 2, é possível perceber indícios mudanças de sentido sobre o lúdico que foram refletidas nas práticas propostas na organização do ensino, no qual a professora Telma relatou ter apresentado às crianças lendas do folclore brasileiro através de contação de histórias, vídeos e confecção de fantoches. Em seguida, realizou um gráfico com as fotos das crianças para representar cada voto em relação à preferência das lendas apresentadas, como mostram as figuras abaixo:

Figura 2 - Plano de Aula 2 (Telma) desenvolvido com turma da Educação Infantil

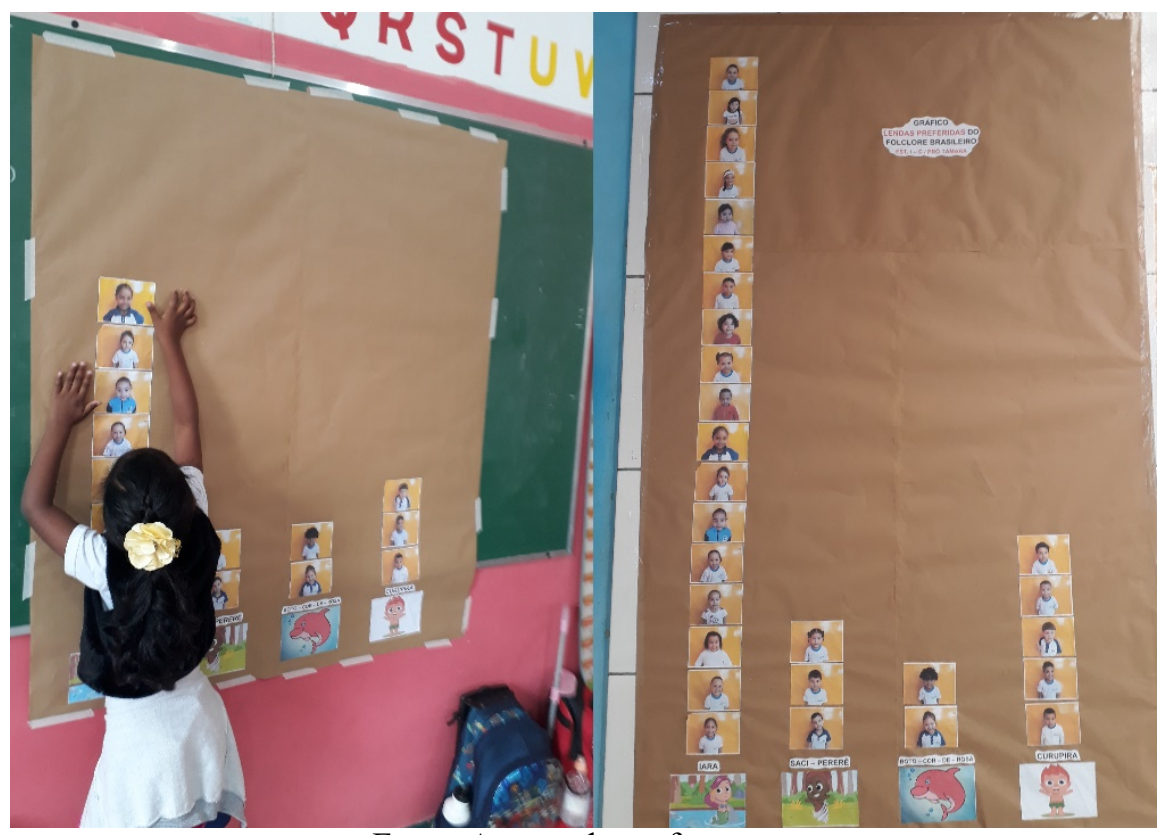

Fonte: Acervo da professora. 
A prática de contar histórias está atrelada à ludicidade porque a história pode gerar uma "atividade imaginativa" que pode criar um espaço para buscar soluções e participar coletivamente (SANTANA, 2018, p.65). Além disso, ao contar história possibilitamos:

Ao ouvinte imaginar situações não vivenciadas, relembrar momentos vividos, a possibilidade de levar o conhecimento da história vivida e, também, da história da humanidade. Nas aulas de matemática, representam um outro olhar para o aprender Matemática com ludicidade, envolvimento, imaginação e criatividade (ANDRADE e GRANDO, 2007, p. 2)

Portanto, analisando a organização do ensino proposta no plano aula 2 e o relato pessoal da prática da professora Telma, reconhecemos que houve um movimento de sentidos pessoais sobre o lúdico, que passa a ser mediador das práticas da professora em sala de aula. Temos que, ao planejar e desenvolver seu segundo plano de aula, a ludicidade foi contemplada por meio da leitura de lendas folclóricas e com o uso de fantoches, considerando a atividade principal da criança. Essas ações intencionais da professora se aproximam da proposta da AOE (MOURA, 1996) e suscitaram nas crianças a necessidade de registrar a quantidade que representava a preferência dos colegas, além de permitir a apropriação de elementos da cultura nacional.

Nesse movimento, ao atribuir ao lúdico o sentido de mediador da prática que pode desencadear uma situação de aprendizagem de determinado conceito matemático, parece que o sentido inicial da professora que associava a ideia de ludicidade à concretude, como prática essencial na organização de práticas de Educação Matemática, dá indícios de ser superado. Assim, o movimento do sentido sobre a ludicidade impactou a organização práticas de Educação Matemática, resultando em uma transformação de suas ações em sala de aula.

Ao analisar os indícios de mudanças de sentidos entre os planos de aula 1 e 2 da professora Telma, podemos encontrar o seguinte movimento: 
Figura 3 - Práticas de Educação Matemática e sentidos pessoais da professora Telma - Planos de aula 1 e 2

\section{Proposta desenvolvida:}

Plano de aula 1: Brincadeira musical com a turma na área externa; manuseio de objetos concretos para representar quantidades em sala.

Plano de aula 2: Apresentação das lendas folclóricas; gráfico de lendas preferidas da turma.

\section{Indícios de movimento de sentidos:}

Plano de aula 1: O lúdico passa a ser uma parte da proposta da professora, mas não é mediador, que continua sendo a concretude.

Plano de aula 2: O lúdico é mediador da prática proposta (vivência da história) e também suscita a necessidade na elaboração do gráfico.

Fonte: Das autoras.

\section{O ESPAÇO COLETIVO DE FORMAÇÃO DE EDUCADORES MATEMÁTICOS: CONTRIBUIÇÕES PARA AS PRÁTICAS EM SALA DE AULA}

Ao analisar os indícios de movimentos de sentidos pessoais da professora Telma sobre o lúdico ao longo do percurso formativo em espaço coletivo, percebemos que o processo de apropriação de conceitos teóricos sobre ludicidade e sobre a organização do ensino teve um impacto direto em seus sentidos pessoais e nas suas práticas de Educação Matemática com sua turma.

Figura 4 - Movimentos da professora Telma em contexto formativo

\begin{tabular}{|c|c|c|}
\hline $\begin{array}{c}\text { Sentidos } \\
\text { iniciais sobre o } \\
\text { lúdico. }\end{array}$ & $\begin{array}{l}\text { paço coletivo de } \\
\text { formação. }\end{array}$ & $\begin{array}{l}\text { Movimentos de } \\
\text { sentidos sobre o } \\
\text { lúdico. }\end{array}$ \\
\hline $\begin{array}{l}\text { Lúdico } \\
\text { entendido como } \\
\text { concretude. }\end{array}$ & $\begin{array}{c}\text { Apropriação de } \\
\text { conceitos teóricos e } \\
\text { produção coletiva de } \\
\text { práticas. }\end{array}$ & $\begin{array}{l}\text { Lúdico passa a ser } \\
\text { mediador e } \\
\text { mobilizador da prática. }\end{array}$ \\
\hline
\end{tabular}

Na figura 4 apresentamos uma síntese do movimento de sentidos da professora Telma ao longo do contexto formativo. Como demonstramos na análise dos dados, a professora Telma inicia o percurso formativo relacionando o lúdico à concretude e, ao apropriar-se da teoria ao longo da formação e trabalhar coletivamente no grupo de formação, passa a produzir sentidos pessoais que impactam e alteram a organização de práticas. Além do movimento de apropriação da teoria, o espaço coletivo de escuta, diálogo 
e planejamento, constituiu-se com um importante elemento que impactou o movimento dos sentidos pessoais da professora.

A coletividade favoreceu alterações nas práticas de Educação Matemática da professora Telma entre os dois planos de aula por meio de um processo social de relato, avaliação e replanejamento das ações com as turmas, influenciando também na transformação dos sentidos da professora Telma sobre o lúdico. A importância da coletividade é corroborada pelas contribuições da Teoria Histórico-Cultural (VIGOTSKI, 2010) e é fundamental nas ideias de Clubes de Matemática (CEDRO, 2004), como espaço de trabalho conjunto e mediação dos pares no processo de apropriação de conhecimentos, conceitos, valores que constituem o desenvolvimento humano. Esse espaço constituído durante a formação mobilizou as professoras, possibilitando que elas constituíssem novas perspectivas sobre as práticas e modos de organizar o ensino em sala de aula.

Esse movimento em grupo foi de extrema importância em nossa pesquisa, pois consideramos que a coletividade propicia apropriações para alunos em sala de aula, mas também para professores em formação, porque "vemos aqui ilustrados dois níveis de participação do sujeito no ato de aprender: o do educador que aprende como ensinar e porque participa de sua própria formação, conhece como propor a participação ativa da criança, ao aprender" (LANNER DE MOURA e MOURA, 1998).

$\mathrm{Na}$ análise do movimento de sentido sobre ludicidade da professora Telma, apresentado nesse artigo, mostramos que nesse processo os motivos da professora para inserir elementos lúdicos na atividade de ensino foram impactados, o que implicou em mudanças na organização de suas práticas de educação matemática. O reconhecimento, pela professora, da importância da ludicidade na organização de práticas de Educação Matemática para a Educação Infantil, resulta do movimento de sentidos da professora que foi possível em um processo de apropriação de significações sociais mediado pelas ações de formação desenvolvidas, de modo que "conscientização dos conhecimentos se caracteriza precisamente pela natureza dos sentidos que eles tenham para o homem" (LEONTIEV, 1983, tradução nossa).

A partir da questão investigada sobre a relação entre os sentidos das professoras em relação ao lúdico e a organização do ensino, esta pesquisa pode contribuir para evidenciar o papel das práticas lúdicas no processo de ensino e aprendizagem de matemática. 
Entendendo essas vivências para além dos jogos e brincadeiras, mas incluindo também propostas como as histórias, situações emergentes do cotidiano, histórias virtuais e rodas de conversas que podem mobilizar as crianças de maneira efetiva e essencial para seu desenvolvimento, o professor pode desenvolver práticas organizadas intencionalmente para serem vivenciadas em todas as fases da educação escolar, seja na Educação Infantil ou Ensino Fundamental, uma vez que o brincar é uma atividade fundamental e desenvolvente da infância.

Todas essas contribuições sobre o lúdico, sobre espaços coletivos e importância do educador como sujeito em atividade nos dão indícios da importância da formação continuada de professores como um caminho essencial para que as práticas em sala de aula e a organização do ensino possam permear sempre o debate, fazendo parte de discussões e contribuindo para apropriações teóricas por parte desses sujeitos que ensinam; de modo que esses processos possam mobilizá-los nas práticas em sala de aula, propiciando que os alunos aprendam coletivamente, se apropriem de conhecimentos matemáticos e outros elementos culturais construídos histórica e socialmente, desenvolvam seu psiquismo e, portanto, humanizem-se.

\section{REFERÊNCIAS}

ANDRADE, D. de O., GRANDO, R. C. Contando histórias nas aulas de matemática: Produção/mobilização de conceitos na perspectiva da resolução de problemas. 2007. Trabalho apresentado no GT: Educação Matemática/n.19. Anais da 30a Reunião Científica da ANPEd. Caxambu, outubro de 2007. Disponível em: https://anped.org.br/sites/default/files/gt19-3742-int.pdf. Último acesso: 27 de fevereiro de 2020, às 18:32.

ANDRADE, J. R. Práticas lúdicas e a organização do ensino de Matemática: Movimento dos sentidos na formação docente. Dissertação (Mestrado em Educação). Guarulhos: Universidade Federal de São Paulo, 2020. Disponível em: http://www.ppg.educacao.sites.unifesp.br/images/dissertacoes/2020/21.-Juliana-RibeiroAndrade.pdf. Último acesso: 12 de março de 2021, às 00:50.

CEDRO, W. L. O espaço de aprendizagem e a atividade de ensino: o clube da matemática. Tese (Doutorado em Educação). São Paulo: Universidade de São Paulo, Faculdade de Educação, 2004.

CEDRO, W. L., MOURA, M. O. Possibilidades metodológicas na pesquisa em educação matemática: o experimento didático. Educativa, Goiânia, v. 15, n. 1, p.25-38, jan./jun. 2012. 247 Disponível em: http://seer.pucgoias.edu.br/ index.php/edu cativa/article/view/2439/1501. Último acesso: 14 de dezembro de 2019, às 19:12. 
DAVIDOV, V. V.; MÁRKOVA, A. (1987). La concepcion de la actividad de estudio de los escolares. In: DAVIDOV, V.; SHUARE, M. (Orgs.), La psicología evolutiva y pedagogía en la URSS: antología. (pp.316-337). Moscou: Progreso.

FACCI, M. G. D. A periodização do desenvolvimento psicológico individual na perspectiva de Leontiev, Elkonin e Vigotski. Cad. Cedes, Campinas, vol. 24, n. 62, p.6481, abril, 2004. Disponível em: http://www.scielo.br/scielo.php?script=sci_abst ract\&pid= S0101- 32622004000100005\&lng=en\&nrm=iso\&tlng=pt. Último acesso: 14 de dezembro de 2019, às 19:50.

GRANDO, R. C. O jogo na Educação Matemática: aspectos teóricos e metodológicos. In: GRANDO, R. C. O jogo e a matemática no contexto da sala de aula. São Paulo: Paulus, 2008. Cap 1, p.17-38.

LEONTIEV, A. N. Sobre o desenvolvimento histórico da consciência. In: LEONTIEV, A. N. O desenvolvimento do psiquismo. Horizonte Universitário. p.89-113, 1978a.

O desenvolvimento do psiquismo na criança. In: LEONTIEV, A.

N. O desenvolvimento do psiquismo. Horizonte Universitário. p.285-315, 1978b.

. Uma contribuição à teoria da psique infantil. In: VIGOTSKI, L. et al. Linguagem, desenvolvimento e aprendizagem. São Paulo: Ícone, 1988. Cap.4, p.59-83.

Educación, 1983.

. Actividad, consciencia, personalidad. Havana: Editorial Pueblo y

MORETTI, V. D. Aprendizagem da docência em atividade de ensino no clube da matemática. Revista Quadrimestral da Associação Brasileira de Psicologia Escolar e Educacional, SP. Volume 18, Número 3, Setembro/Dezembro de 2014. Disponível em: http://dx.doi.org/10.1590/2175-3539/2014/0183779. Último acesso: 14 de dezembro de 2019 , às $21: 30$.

MORETTI, V. D., MARTINS, E. SOUZA, F. D. Método Histórico-Dialético, Teoria Histórico-Cultural e educação: algumas apropriações em pesquisas sobre formação de professores que ensinam matemática. RIPEM V.6, N.2, 2016, p.54-72.

MOURA, M. O. Controle da variação de quantidades: atividades de ensino. São Paulo: FEUSP, 1996.

- Saberes pedagógicos e saberes específicos: desafios para o ensino de Matemática. Anais do XIII Encontro Nacional de Didática e Prática de Ensino XIIIEndipe, v. 13, p. 489-504, 2006.

. Matemática na Infância (2002). In Miguéis, M. \& Azevedo, G. (Orgs.). Educação Matemática na Infância. Abordagens e desafios. 1 ed. Vila Nova de Gaia/Portugal: Gailivro, 2007, p.39-63.

. et al. Atividade orientadora de ensino: unidade entre ensino e aprendizagem. Revista Diálogo Educacional, v. 10, n. 29, p.205-229, 2010.

MOURA, M. O., LANNER DE MOURA., A. R. Matemática para a Educação Infantil. In: MOURA, M. O., LANNER de M., A. R. Escola: um espaço cultural. Matemática na educação infantil: conhecer, (re)criar - um modo de lidar com as dimensões do mundo. São Paulo: Diadema/SECEL, 1998. 
SANTANA, E. D. de. A literatura infantil como recurso lúdico para a aprendizagem. Revista científica de iniciación a la investigación, v 03, n 1, Assunção, 2018. Disponível em: http://revistacientifica.uaa.edu.py/index.php/rcuaa/article/view/422. Último acesso: 27 de fevereiro de 2021, às 19:41.

VIGOTSKI, L. S. A formação social da mente. São Paulo: Martins Fontes, $4^{\mathrm{a}}$ edição, 1998.

. O problema e o método de investigação. In: VIGOTSKI, L. S. A construção do pensamento e da linguagem. Tradução de Paulo Bezerra. São Paulo: Martins Fontes, $1^{\mathrm{a}}$ edição. P. 1-18, 2001.

. Aprendizagem e desenvolvimento intelectual na idade

escolar. In: VIGOTSKI, L. S., LURIA, A. R., LEONTIEV, A. N. Linguagem, desenvolvimento e aprendizagem. Tradução de Maria da Pena Villalobos. São Paulo: Ícone, $11^{\mathrm{a}}$ edição. P. 103- 117, 2010.

. Quarta aula: a questão do meio na pedologia. Tradução de Márcia Pileggi Vinha. Psicologia USP, vol. 21, no.4, São Paulo, 2010. Disponível em: https://www.scielo.br/scielo.php?script=sci_arttext\&pid=S0103-65642010000400003.

Último acesso: 06 de maio de 2020, às 18:44.

Submetido em 25 de abril de 2021. Aprovado em 27 de abril de 2021. 